Justin Clarke-Doane

Columbia University

[This is a penultimate draft of a paper that is forthcoming in Higher Order Evidence and Moral Epistemology edited by Michael Klenk.]

\title{
Epistemic Non-Factualism and Methodology ${ }^{1}$
}

I discuss methodology in epistemology. I argue that settling the facts, even the epistemic facts, fails to settle the questions of intellectual policy at the center of our epistemic lives. An upshot is that the standard methodology of analyzing concepts like knowledge, justification, rationality, and so on is misconceived. More generally, any epistemic method that seeks to issue in intellectual policy by settling the facts, whether by way of abductive theorizing or empirical investigation, no matter how reliable, is inapt. The argument is a radicalization of Moore's Open Question Argument. I conclude by considering the ramifications of this conclusion for the debate surrounding "Modal Security", a proposed necessary condition on undermining defeat.

\section{The Prospect of Pluralism}

In his [2005], Alston argues that certain debates in epistemology might be merely verbal. One party may be using the target word in one way, while the other is using it in another. If Alston is right, then paradigmatic debates in epistemology would be like a "debate" between moving observers over the simultaneity of two events. There would be a plurality of properties in the

\footnotetext{
${ }^{1}$ Thanks to J. Adam Carter Michael Klenk, Christos Kyriacou, Chris Scambler, and Justin Vlasits for helpful comments.
} 
neighborhood, giving intuitively opposite verdicts on the question of whether X's belief that $\mathrm{P}$ counts as knowledge, or is justified, or is supported by some evidence, and each party may be right of one of them. ("Intuitively" because the rival properties would strictly give verdicts on different questions -- questions of knowledge1 and knowledge2, say -- as with simultaneity.)

What would become of epistemological debates if Alston were right? It might be thought that they would go away, just like debates about simultaneity. We have given up the question of what is simultaneous with what in favor of the question of what is simultaneous with what relative to $\mathrm{R}$, for variable reference frame, $\mathrm{R}$. We would likewise give up the question of whether X's belief counts as knowledge, or is justified, or is supported by some evidence. There would be different properties in the neighborhood, and all sides could agree that X's belief exemplified one but not another. There would be no question left to ponder.

However, there is an essential difference between the cases. Epistemology is normative, while physics is not. Whatever that means exactly, it at least it means that the truths it discovers about knowledge, justification, evidence, and on typically issue in policy. They issue in what to do, believe, infer, and so forth. It would be bewildering if an epistemologist were to say: "the evidential support relation is, $\mathrm{R}$, but do not worry about having beliefs that bear $\mathrm{R}$ to the evidence" (much as it would be if an ethicist were to say: "goodness is property G, but do not worry about seeking things that are G"). It would just invite the question: "why care about evidential support?" There are myriad properties that epistemologists could investigate. What makes knowledge, justification, and so on important is their connection to intellectual policy. 
This means that pluralism in epistemology would be a problem in a way that pluralism is not in the case of simultaneity. There would be a residue of policy questions which would be left unresolved by the epistemic facts. There would be justification1, knowledge1, and evidential support1, as well as justification2, knowledge2, and evidential support2. Learning that, e.g., our belief that $\mathrm{P}$ is supported 1 by the evidence, but not supported 2 would leave the policy question unanswered: whether to believe $P$. And while it might be thought that this question would just be resolved by a higher-order fact about which properties we epistemically ought to consult, that assumes that Alston's worries do not arise for terms like "epistemically ought" themselves. If they did, then while we epistemically ought 1 consult properties $\mathrm{P}_{1}, \mathrm{P}_{2}, \ldots$ we epistemically ought 2 consult properties $\mathrm{Q}_{1}, \mathrm{Q}_{2}, \ldots$. Our original question would merely get transposed. The policy question would now be whether to do what we epistemically ought 1 or ought 2 to do.

\section{$\underline{\text { Illusive Questions }}$}

I have been writing as if epistemological facts would fail to settle policy questions only if Alston were right about natural language semantics. There is no problem so long as he is wrong, and we all happen to use "knowledge", "justification", and so on in the same way. But, actually, a problem like the above arises in any case. Let us grant that epistemic terms are systematically univocal. We can always stipulatively introduce epistemic-like terms which diverge in extension (Eklund [2017]). And now the policy question simply rearises: whether to consult these new properties or the old ones when regulating our beliefs, inferences, and practices generally. 
Could this question be settled by the epistemic facts? It could not, on pain of triviality. If the epistemic facts are good for anything, then they are self-sanctioning in the sense that we epistemically ought to use epistemic ought. But this banality does not help us. We epistemically ought to use epistemic ought. We also epistemically* ought to use epistemic* ought, for various alternative epistemic-like properties (or operators), epistemic ought*.2 Whenever ought-like concepts diverge in extension, they issue in conflicting policy. We are left with the question of which to follow. On pain of triviality, this cannot turn on the question of which we ought to follow

This argument suggests that epistemic facts, even if there are any, and even if they are the (determinate) subject of epistemic debates, fail to settle questions at the center of our epistemic lives. The argument is actually an example of a more general one. In his [1903, Section 13] Moore noted that an agent may believe that $\mathrm{A}$ is $\mathrm{F}$, for any descriptive property, $\mathrm{F}$, while failing to judge that A is morally good. ${ }^{3}$ For instance, if A is prioritizing one's offspring, then she may believe that this is natural, or that it is what we would desire to desire, or that it would maximize a certain psychological state, while failing to judge that doing this is morally good. However, there is a sense in which Moore's point can be generalized even to evaluative properties, like goodness, themselves (Clarke-Doane [2015], [Forthcoming]). An agent may believe that A is F, for any property whatever, while failing to "endorse" $\mathrm{A}$ in the sense that is characteristic of practical deliberation. This is because she may always wonder whether to do what is $\mathrm{F}$, rather than $\mathrm{F}^{*}$, for some alternative F-like property, $\mathrm{F}^{*} .{ }^{4}$ As Blackburn puts it, "[e]ven if [a moral]

\footnotetext{
${ }^{2}$ I borrow the star notation from Eklund [2017].

${ }^{3}$ See Greco [2015] for an epistemic analog of Moore's argument.

${ }^{4}$ And not just in the sense that we all threaten to be weak in will.
} 
belief were settled, there would still be issues of what importance to give it, what to do, and all the rest....For any fact, there is a question of what to do about it $[1998,70]$." Settling the facts, even the evaluative facts, fails to settle the policy questions at the center of our evaluative lives.

It might be objected that this "New Open Question Argument" merely shows that we have failed to identify the facts that settle policy questions. Perhaps, for instance, it is facts about which epistemic-like properties we ought to consult in some non-epistemic sense of "ought", whether moral, prudential, or all-things-considered (Das [Forthcoming]). Many epistemologists would hold that epistemic norms are not overriding. Sometimes we ought to do what we epistemically ought not. If a gun is put to my head with the credible threat that my friend will be killed unless I believe that the number of stars is even, then I ought to believe, though I epistemically ought not. But if the argument works, then it works for any evaluative terms -- whether moral, prudential, epistemic, or all-things-considered. Even if we all-things-considered ought to consult epistemic properties, we all-things-considered ought* not. And the policy question just re-arises whether to do what we all-things-considered ought, or all-things-considered ought*, to do.

Nor could the remaining question be one of speculative metaphysics. We know from Goodman [1983] that having true beliefs about a subject is one thing, and "getting it right" is another. Getting it right at least arguably requires having true beliefs that ascribe natural kinds. So, one might be tempted to suggest that the question of which epistemic-like properties to consult turns on the metaphysical question of which epistemic-like properties are natural kinds. ${ }^{5}$ But either the

\footnotetext{
${ }^{5}$ Perhaps this is what Werner means in speaking of "concepts [that] adequately characterize the robustly normative properties [Werner 2017, 9]", or what McPherson means by "authoritatively normative" [Forthcoming b].
} 
question of which epistemic-like properties are natural kinds is itself evaluative or not. If not, then Moore's Open Question Argument applies. Learning that epistemic ought is a natural kind would be like learning that it is heavy. It would be neither here nor there from the standpoint of policy. But if the question of which epistemic-like properties are natural kinds is evaluative, then the argument can just be re-run vis a vis natural kind-hood. Even if epistemic ought is a natural kind, it is not a natural* kind, for some naturalness-like concept, natural*, and now the question is whether to theorize in terms of natural or natural* kinds (Dasgupta [2017]).

Maybe policy questions turn on an ineffable question of fact (Eklund [2017])? It does not seem so. There are two ways in which the target propositions -- call them "policy propositions" -could be ineffable. First, they could be structurally ineffable in the sense of Hofweber [2017]. Their ineffability could be due to their failure to share anything like sentential structure. But, if this were so, then it would be impossible to explain the connection between our linguistic behavior with epistemic sentences and the policy propositions we ponder. If you utter S and I reply $\sim \mathrm{S}$, where $\mathrm{S}$ is an epistemic sentence, then we should at least be able to conclude that the policy propositions that we believe are inconsistent (even if they are not expressed by the sentences, $\mathrm{S}$, and $\sim \mathrm{S}$ ). But if those propositions are structurally ineffable, then we do not even know whether "consistency" makes sense as applied to them -- since we do not know whether there is any operation on them corresponding to sentential negation. So, it is more promising to suggest that policy propositions are ineffable because, while they share sentential structure, policy properties are ineffable. If this is why policy propositions are ineffable, however, then we can simply reformulate the problem that policy propositions were supposed to solve. If there are 
a plurality of epistemic-like facts, then there are a plurality of policy-like facts as well. (Whether those facts are effable is neither here nor there.) And the question remains which to consult. ${ }^{6}$

\section{Non-Factualism and Methodology}

So, the policy questions at the center of our evaluative lives are not settled by the facts -- whether evaluative or not. Since the only way this could be is if those questions are not themselves questions of fact, it follows that the policy questions at the center of our evaluative lives are not questions of fact. They are the questions of "what importance to give [the facts], what to do, and all the rest" which remain after the facts are settled. In particular, even if there are epistemic facts, and even if they are the subject of typical epistemological debate, a central goal of any normative discipline like epistemology must be to issue in policy. And not even epistemic facts can do that -- for much the reason that they could not if Alston were right about semantics.

This conclusion, if correct, has significant ramifications for epistemic methodology. Consider what is perhaps the standard methodology in epistemology, conceptual analysis. We consider cases, and ask what we would "say". Paradigms include Gettier [1966]'s "counterexamples" to the justified-true-belief analysis of knowledge, Goldman [1976]'s fake barn case, and Bonjour [1980]'s clairvoyant Norman. There is considerable debate about whether conceptual analysis is a reliable means by which to determine the facts about knowledge, justification, and so on. But, for our purposes, we can assume that the methodology is infallible. What is important is that this

\footnotetext{
${ }^{6}$ Nor could the further fact be a mind-dependent question one a la Street [2006, Sec. 7] or Korsgaard [1996]. Again, if this "New Open Question Argument" works, it works equally to show that the evaluative facts constructivistically construed fail to settle policy questions. For instance, just as we can wonder whether to do what we ought1 as opposed to ought2 to do, realistically construed, we can wonder whether to be an agent or a shmagent (Enoch [2006]).
} 
is not enough to show that results arrived at by way of conceptual analysis settle intellectual policy. For that assumes that we ought to defer to the concepts that we happen to have inherited. ${ }^{7}$ Even if we could accumulate "epistemic theorems" as robust as Euclid's, maybe our epistemic concepts are corrupt, or merely sub-maximal. In that case, we could agree with Gettier, Goldman, Bonjour, and so on completely about the epistemic facts while disagreeing with them in the way that matters. We could advocate consulting epistemic*, rather than epistemic, facts.

Let us consider a contemporary example. "Modal Security" is a currently discussed proposed necessary condition on undermining defeat (Clarke-Doane [2015], [Forthcoming, Chapter 4]). At first approximation, it says that if evidence undermines (rather than rebuts) our belief, then it gives us reason to doubt the belief's modal security. The intuition is that if evidence neither tells directly against $\mathrm{P}$ (as it would if it were rebutting), nor against the security of our belief as to whether P, then it makes no sense to give it up. More carefully, the principle reads as follows.

Modal Security: If evidence, E, undermines our belief that $\mathrm{P}$, then $\mathrm{E}$ gives us direct reason to doubt that our belief is sensitive or safe or $\mathrm{E}$ undermines the belief that $<$ the belief that $\mathrm{P}$ is safe and sensitive> (Baras and Clarke-Doane [Forthcoming]).

Sensitivity and safety are defined as follows.

\footnotetext{
${ }^{7}$ See Stich [1990] for a worry in the same spirit as this one.
} 
Sensitivity: Our belief that $\mathrm{P}$ is sensitive just in case had it been that $\neg \mathrm{P}$, we would not still have believed that P (had we used the method that we actually used to determine whether P).

Safety: Our belief that $\mathrm{P}$ is safe just in case we could not have easily had a false belief as to whether or not $\mathrm{Q}$, where $\mathrm{Q}$ is any proposition similar enough to $\mathrm{P}$ (using the method that we actually used to determine whether or not P).

The primary interest of Modal Security is its bearing on epistemological arguments against realism. The two most prominent examples are Genealogical Debunking Arguments against moral realism, and the Benacerraf-Field Challenge against mathematical realism. If Modal Security is true, then all such arguments would seem to fail (Clarke-Doane [Forthcoming, Chapter 4]). Consequently, there has been considerable interest in whether it is true.

For our purposes, it does not matter whether Modal Security is true, however. What matters is the relevance of arguments for and against it to question of intellectual policy. The most prominent argument against it is that knowledge that P requires a "connection", whether causal or not, between our belief that P and the fact that P (Faraci [2019], Locke and Korman [Forthcoming]). It does not suffice that our belief that $\mathrm{P}$ is safe and sensitive. If knowledge is the norm of belief, and evidence that our belief that $\mathrm{P}$ fails to satisfy that norm undermines whatever justification the belief enjoyed, then evidence that there is no connection between our belief that $\mathrm{P}$ and the fact that $\mathrm{P}$ undermines that belief -- even if it fails to tell against our belief's 
safety or sensitivity. Since Modal Security says that it does not, Modal Security is false if this argument is sound. ${ }^{8}$

Let us suppose that knowledge that $\mathrm{P}$ does require a connection between our belief that $\mathrm{P}$ and the fact that P; that knowledge is the norm of belief; that evidence that a belief falls short of that norm undermines it; and, hence, that Modal Security is false. Shall we adopt the policy of giving up (defeasibly) justified beliefs in light of evidence that neither tells directly against their contents nor against the security of their truth on this basis alone? Surely not. The argument above just tells us what is "packed into" the concepts we happen to have inherited -- or, semantically descending, the conditions under which the corresponding properties are instantiated. This does nothing evidently to tell us how to regulate our beliefs (even if it does settle the question of how we epistemically ought to regulate them). Indeed, if our goal is anything like having true beliefs, then giving up a (defeasibly) justified belief on the ground that it lacks a "connection" to the truth would seem to be like giving it up because it is not polite. The truth-seekers among us would seem better served by opting out of such epistemic etiquette.

My point is not to advocate the policy of abiding by Modal Security. It is that its truth per se is of doubtful relevance to the policy question. An advocate of Modal Security who is convinced that knowledge requires a connection between our belief and the truth will just advocate aspiring to knowledge* instead -- where knowledge* is like knowledge, but does not require a connection between our belief and the truth. She is like one who advocates not retributing against the

\footnotetext{
${ }^{8}$ See Bergmann [1997] for other reasons one might think that Modal Security is false.
} 
responsible. If deserving retribution is "packed into" the concept of responsibility, then such a person will just advocate holding people responsible* instead -- where responsibility* is like responsibility, except that one can be responsible* without deserving (or deserving*) retribution. Settling the epistemic, and generally evaluative, facts fails to settle the policy questions at issue.

Of course, the methodology of conceptual analysis has been widely criticized for reasons that are independent of the present discussion. But it should be clear that the problem above is not peculiar to it. It arises equally for any method that seeks to decide on epistemic policy by determining the epistemic facts. This includes the abductive methodology of Williamson [2007], and the naturalistic methodology of Quine [1969], no less than the method of conceptual analysis. The policy questions at stake in epistemology, as in other evaluative domains, are not questions of what we ought to do or believe. They are questions of what to do or believe. And these questions remain open even when the facts, including the evaluative ones, are closed.

\section{$\underline{\text { Conclusion }}$}

I have argued that knowledge of the epistemic facts fails to settle the policy questions at the center of our epistemic lives. This means that the standard method of analyzing concepts like knowledge, justification, and so on is misconceived. But it means something stronger. It means that settling the facts, whether by conceptual analysis or in any other way, is an inappropriate method by which to arrive at intellectual policy. For example, if "the implication relation [classically] defined agrees with the pre-theoretic notion of implication between statements 
[Zach Forthcoming, 1]", then the policy question just gets transposed. The question is now whether to use our pre-theoretic notion or another. This argument is a radicalization of Moore's.

Note that I have not argued that "anything goes". That would only follow if policy questions failed to be settled at all if they failed to be settled by the facts. But, as non-cognitivists have long argued, this does not follow. Policy questions -- whether moral, epistemic, or prudential -are settled by practical reasoning. The point is that such reasoning is not reducible to reasoning about the facts. Policy questions are impervious to how plentiful the facts turn out to be.

\section{Bibliography}

Alston, William. [2005] Beyond "Justification": Dimensions of Epistemic Evaluation. Ithaca: Cornell University Press.

Baras, Dan and Justin Clarke-Doane. [Forthcoming] "Modal Security”. Philosophy and Phenomenological Research.

Bergmann, Michael. [1997] “Internalism, Externalism, and Epistemic Defeat.” PhD Dissertation: University of Notre Dame.

BonJour, L. 1980. "Externalist Theories of Empirical Knowledge," Midwest Studies in Philosophy 5, 53-73.

Blackburn, Simon. [1998] Ruling Passions. Oxford: Clarendon Press.

Clarke-Doane, Justin. [2015] "Objectivity in Ethics and Mathematics," Ben Colburn (ed.), Proceedings of the Aristotelian Society, The Virtual Issue, No. 3 (Methods in Ethics). Available online at: $<$ http: $/ / w w w . a r i s t o t e l i a n s o c i e t y . o r g . u k / p d f / 2015$ virtual_issue.pdf $>$ 
-----. [Forthcoming] Morality and Mathematics. Oxford: Oxford University Press.

Das, Ramon. [Forthcoming] “Moral Pluralism and Companions in Guilt.” in Cowie, Christopher and Richard Rowland (eds.), Companions in Guilt Arguments in Metaethics. Routledge.

Dasgupta, Shamik. [2017] "Normative Non-Naturalism and the Problem of Authority."

Proceedings of the Aristotelian Society. Vol. 3. 297-319.

Eklund, Matti. [2017] Choosing Normative Concepts. Oxford: Oxford University Press.

Moore, G.E. [1903] Principia Ethica. Available online at:

$<\underline{\text { http://fair-use.org/g-e-moore/principia-ethica }>}$

Enoch, David. [2006] “Agency, Shmagency: Why Normativity Won't Come from What Is

Constitutive of Action." Philosophical Review. Vol. 115. 169-198.

Faraci, David. [2019] "Groundwork for an Explanationist Account of Epistemic Coincidence."

Philosophers' Imprint. Vol. 19. Available online at:

$<\underline{\text { https://quod.lib.umich.edu/p/phimp/3521354.0019.004/1> }}$

Gettier, Edmund. [1966] “Is Justified True Belief Knowledge?” Analysis. Vol. 23. 121-123.

Goldman, Alvin. [1976] “Discrimination and Perceptual Knowledge.” The Journal of

Philosophy. Vol. 73. 771-791.

Goodman, Nelson. [1983] Fact, Fiction, and Forecast (4th Edition). Cambridge, MA: Harvard University Press.

Greco, Daniel. [2015] “Epistemological Open Questions.” Australasian Journal of Philosophy.

Vol. 93. 509--522. 
Hofweber, Thomas. [2017] “Are There Ineffable Aspects of Reality?” in Bennett, Karen, and Dean Zimmerman (eds.), Oxford Studies in Metaphysics, Vol. 2. Oxford: Oxford University Press. 155-206.

Korsgaard, Christine. [1996] The Sources of Normativity. New York: Cambridge University Press.

Locke, Dustin and Dan Korman. [Forthcoming] “Against Minimalist Responses to Moral Debunking Arguments." Oxford Studies in Metaethics.

McPherson, Tristram. [Forthcoming] “Authoritatively Normative Concepts." Shafer-Landau (ed.), Oxford Studies in Metaethics. Available online at:

$<\underline{\text { ttps://philpapers.org/archive/MCPANC.pdf }}>$

Quine, W.V.O. [1969] "Epistemology Naturalized." in Ontological Relativity and Other Essays. New York: Columbia University Press.

Stich, Stephen. [1990] The Fragmentation of Reason Cambridge, MA: MIT.

Street, Sharon. [2006] “A Darwinian Dilemma for Realist Theories of Value.” Philosophical Studies. Vol. 127. 109-166.

Werner, Preston. [2018] “Why Conceptual Competence Won’t Help the Non-Naturalist Epistemologist." Canadian Journal of Philosophy. Vol. 48. 616-637.

Zach, Richard. [Forthcoming] "Rumfitt on Truth-Grounds, Negation, and Vagueness."

Philosophical Studies. Available online at: $<$ https://philarchive.org/archive/ZACROT-3> 